\title{
A Surgical Safety Checklist to Reduce Morbidity and Mortality in a Global Population
}

\section{Citation}

Haynes, Alex B., Thomas G. Weiser, William R. Berry, Stuart R. Lipsitz, Abdel-Hadi S. Breizat, E. Patchen Dellinger, Teodoro Herbosa, et al. 2009. "A Surgical Safety Checklist to Reduce Morbidity and Mortality in a Global Population." New England Journal of Medicine 360 (5): 49199. https://doi.org/10.1056/nejmsa0810119.

\section{Permanent link}

http://nrs.harvard.edu/urn-3:HUL.InstRepos:38846186

\section{Terms of Use}

This article was downloaded from Harvard University's DASH repository, and is made available under the terms and conditions applicable to Other Posted Material, as set forth at http:// nrs.harvard.edu/urn-3:HUL.InstRepos:dash.current.terms-of-use\#LAA

\section{Share Your Story}

The Harvard community has made this article openly available. Please share how this access benefits you. Submit a story.

Accessibility 


\section{A Surgical Safety Checklist to Reduce Morbidity and Mortality in a Global Population}

\author{
Alex B. Haynes, M.D., M.P.H., Thomas G. Weiser, M.D., M.P.H., \\ William R. Berry, M.D., M.P.H., Stuart R. Lipsitz, Sc.D., \\ Abdel-Hadi S. Breizat, M.D., Ph.D., E. Patchen Dellinger, M.D., \\ Teodoro Herbosa, M.D., Sudhir Joseph, M.S., Pascience L. Kibatala, M.D., \\ Marie Carmela M. Lapitan, M.D., Alan F. Merry, M.B., Ch.B., F.A.N.Z.C.A., F.R.C.A., \\ Krishna Moorthy, M.D., F.R.C.S., Richard K. Reznick, M.D., M.Ed., Bryce Taylor, M.D., \\ and Atul A. Gawande, M.D., M.P.H., for the Safe Surgery Saves Lives Study Group*
}

ABSTRACT

\section{BACKGROUND}

Surgery has become an integral part of global health care, with an estimated 234 million operations performed yearly. Surgical complications are common and often preventable. We hypothesized that a program to implement a 19-item surgical safety checklist designed to improve team communication and consistency of care would reduce complications and deaths associated with surgery.

\section{METHODS}

Between October 2007 and September 2008, eight hospitals in eight cities (Toronto, Canada; New Delhi, India; Amman, Jordan; Auckland, New Zealand; Manila, Philippines; Ifakara, Tanzania; London, England; and Seattle, WA) representing a variety of economic circumstances and diverse populations of patients participated in the World Health Organization's Safe Surgery Saves Lives program. We prospectively collected data on clinical processes and outcomes from 3733 consecutively enrolled patients 16 years of age or older who were undergoing noncardiac surgery. We subsequently collected data on 3955 consecutively enrolled patients after the introduction of the Surgical Safety Checklist. The primary end point was the rate of complications, including death, during hospitalization within the first 30 days after the operation.

\section{RESULTS}

The rate of death was $1.5 \%$ before the checklist was introduced and declined to $0.8 \%$ afterward $(\mathrm{P}=0.003)$. Inpatient complications occurred in $11.0 \%$ of patients at baseline and in $7.0 \%$ after introduction of the checklist $(\mathrm{P}<0.001)$.

\section{CONCLUSIONS}

Implementation of the checklist was associated with concomitant reductions in the rates of death and complications among patients at least 16 years of age who were undergoing noncardiac surgery in a diverse group of hospitals.
From the Harvard School of Public Health (A.B.H., T.G.W., W.R.B., A.A.G.), Massachusetts General Hospital (A.B.H.), and Brigham and Women's Hospital (S.R.L., A.A.G.) - all in Boston; University of California-Davis, Sacramento (T.G.W.); Prince Hamzah Hospital, Ministry of Health, Amman, Jordan (A.-H.S.B.); University of Washington, Seattle (E.P.D.); College of Medicine, University of the Philippines, Manila (T.H.); St. Stephen's Hospital, New Delhi, India (S.J.); St. Francis Designated District Hospital, Ifakara, Tanzania (P.L.K.); National Institute of Health-University of the Philippines, Manila (M.C.M.L.); University of Auckland and Auckland City Hospital, Auckland, New Zealand (A.F.M.); Imperial College Healthcare National Health Service Trust, London (K.M.); and University Health Network, University of Toronto, Toronto (R.K.R., B.T.). Address reprint requests to Dr. Gawande at the Department of Surgery, Brigham and Women's Hospital, 75 Francis St., Boston, MA 02115, or at safesurgery@hsph.harvard.edu.

*Members of the Safe Surgery Saves Lives Study Group are listed in the Appendix.

This article (10.1056/NEJMsa0810119) was published at NEJM.org on January 14, 2009.

N Engl J Med 2009;360:491-9.

Copyright (c) 2009 Massachusetts Medical Society. 
URGICAL CARE IS AN INTEGRAL PART OF health care throughout the world, with an estimated 234 million operations performed annually. ${ }^{1}$ This yearly volume now exceeds that of childbirth. ${ }^{2}$ Surgery is performed in every community: wealthy and poor, rural and urban, and in all regions. The World Bank reported that in 2002, an estimated 164 million disability-adjusted lifeyears, representing $11 \%$ of the entire disease burden, were attributable to surgically treatable conditions. ${ }^{3}$ Although surgical care can prevent loss of life or limb, it is also associated with a considerable risk of complications and death. The risk of complications is poorly characterized in many parts of the world, but studies in industrialized countries have shown a perioperative rate of death from inpatient surgery of 0.4 to $0.8 \%$ and a rate of major complications of 3 to $17 \% .^{4,5}$ These rates are likely to be much higher in developing countries. ${ }^{6-9}$ Thus, surgical care and its attendant complications represent a substantial burden of disease worthy of attention from the public health community worldwide.

Data suggest that at least half of all surgical complications are avoidable. ${ }^{4,5}$ Previous efforts to implement practices designed to reduce surgicalsite infections or anesthesia-related mishaps have been shown to reduce complications significantly. ${ }^{10-12}$ A growing body of evidence also links teamwork in surgery to improved outcomes, with high-functioning teams achieving significantly reduced rates of adverse events. ${ }^{13,14}$

In 2008, the World Health Organization (WHO) published guidelines identifying multiple recommended practices to ensure the safety of surgical patients worldwide. ${ }^{15}$ On the basis of

Table 1. Elements of the Surgical Safety Checklist.*

Sign in

Before induction of anesthesia, members of the team (at least the nurse and an anesthesia professional) orally confirm that:

The patient has verified his or her identity, the surgical site and procedure, and consent

The surgical site is marked or site marking is not applicable

The pulse oximeter is on the patient and functioning

All members of the team are aware of whether the patient has a known allergy

The patient's airway and risk of aspiration have been evaluated and appropriate equipment and assistance are available

If there is a risk of blood loss of at least $500 \mathrm{ml}$ (or $7 \mathrm{ml} / \mathrm{kg}$ of body weight, in children), appropriate access and fluids are available

\section{Time out}

Before skin incision, the entire team (nurses, surgeons, anesthesia professionals, and any others participating in the care of the patient) orally:

Confirms that all team members have been introduced by name and role

Confirms the patient's identity, surgical site, and procedure

Reviews the anticipated critical events

Surgeon reviews critical and unexpected steps, operative duration, and anticipated blood loss

Anesthesia staff review concerns specific to the patient

Nursing staff review confirmation of sterility, equipment availability, and other concerns

Confirms that prophylactic antibiotics have been administered $\leq 60 \mathrm{~min}$ before incision is made or that antibiotics are not indicated

Confirms that all essential imaging results for the correct patient are displayed in the operating room

Before the patient leaves the operating room:

Sign out

Nurse reviews items aloud with the team

Name of the procedure as recorded

That the needle, sponge, and instrument counts are complete (or not applicable)

That the specimen (if any) is correctly labeled, including with the patient's name

Whether there are any issues with equipment to be addressed

The surgeon, nurse, and anesthesia professional review aloud the key concerns for the recovery and care of the patient

* The checklist is based on the first edition of the WHO Guidelines for Safe Surgery. ${ }^{15}$ For the complete checklist, see the Supplementary Appendix. 
these guidelines, we designed a 19-item checklist intended to be globally applicable and to reduce the rate of major surgical complications (Table 1). (For the formatted checklist, see the Supplementary Appendix, available with the full text of this article at NEJM.org.) We hypothesized that implementation of this checklist and the associated culture changes it signified would reduce the rates of death and major complications after surgery in diverse settings.

\section{METHODS}

\section{STUDY DESIGN}

We conducted a prospective study of preintervention and postintervention periods at the eight hospitals participating as pilot sites in the Safe Surgery Saves Lives program (Table 2). These institutions were selected on the basis of their geographic distribution within WHO regions, with the goal of representing a diverse set of socioeconomic environments in which surgery is performed. Table 3 lists surgical safety policies in place at each institution before the study. We required that a coinvestigator at each site lead the project locally and that the hospital administration support the intervention. A local data collector was chosen at each site and trained by the four primary investigators in the identification and reporting of process measures and complications. This person worked on the study full-time and did not have clinical responsibilities at the study site. Each hospital identified between one and four operating rooms to serve as study rooms. Patients who were 16 years of age or older and were undergoing non- cardiac surgery in those rooms were consecutively enrolled in the study. The human subjects committees of the Harvard School of Public Health, the WHO, and each participating hospital approved the study and waived the requirement for written informed consent from patients.

\section{INTERVENTION}

The intervention involved a two-step checklistimplementation program. After collecting baseline data, each local investigator was given information about areas of identified deficiencies and was then asked to implement the 19-item WHO safe-surgery checklist (Table 1) to improve practices within the institution. The checklist consists of an oral confirmation by surgical teams of the completion of the basic steps for ensuring safe delivery of anesthesia, prophylaxis against infection, effective teamwork, and other essential practices in surgery. It is used at three critical junctures in care: before anesthesia is administered, immediately before incision, and before the patient is taken out of the operating room. The checklist was translated into local language when appropriate and was adjusted to fit into the flow of care at each institution. The local study team introduced the checklist to operating-room staff, using lectures, written materials, or direct guidance. The primary investigators also participated in the training by distributing a recorded video to the study sites, participating in a teleconference with each local study team, and making a visit to each site. The checklist was introduced to the study rooms over a period of 1 week to 1 month. Data collection resumed during the first week of checklist use.

\begin{tabular}{|llccc|}
\hline Table 2. Characteristics of Participating Hospitals. & & & \\
Site & \multicolumn{1}{l}{ Location } & $\begin{array}{c}\text { No. of } \\
\text { Beds }\end{array}$ & $\begin{array}{c}\text { No. of } \\
\text { Operating Rooms }\end{array}$ & Type \\
Prince Hamzah Hospital & Amman, Jordan & 500 & 13 & Public, urban \\
St. Stephen's Hospital & New Delhi, India & 733 & 15 & Charity, urban \\
University of Washington Medical Center & Seattle, Washington & 410 & 24 & Public, urban \\
St. Francis Designated District Hospital & Ifakara, Tanzania & 371 & 3 & District, rural \\
Philippine General Hospital & Manila, Philippines & 1800 & 39 & Public, urban \\
Toronto General Hospital & Toronto, Canada & 744 & 19 & Public, urban \\
St. Mary's Hospital** & London, England & 541 & 16 & Public, urban \\
Auckland City Hospital & Auckland, New Zealand & 710 & 31 & Public, urban \\
\hline
\end{tabular}

* St. Mary's Hospital has since been renamed St. Mary's Hospital-Imperial College National Health Service Trust. 


\section{DATA COLLECTION}

We obtained data on each operation from standardized data sheets completed by the local data collectors or the clinical teams involved in surgical care. The data collectors received training and supervision from the primary investigators in the identification and classification of complications and process measures. Perioperative data included the demographic characteristics of patients, procedural data, type of anesthetic used, and safety data. Data collectors followed patients prospectively until discharge or for 30 days, whichever came first, for death and complications. Outcomes were identified through chart monitoring and communication with clinical staff. Completed data forms were stripped of direct identifiers of patients and transmitted to the primary investigators. We aimed to collect data on 500 consecutively enrolled patients at each site within a period of less than 3 months for each of the two phases of the study. At the three sites at which this goal could not be achieved, the period of data collection was extended for up to 3 additional months to allow for accrual of a sufficient number of patients. The sample size was calculated to detect a $20 \%$ reduction in complications after the checklist was implemented, with a statistical power of $80 \%$ and an alpha value of 0.05 .

\section{OUTCOMES}

The primary end point was the occurrence of any major complication, including death, during the period of postoperative hospitalization, up to 30 days. Complications were defined as they are in the American College of Surgeons' National Surgical Quality Improvement Program ${ }^{17}$ : acute renal failure, bleeding requiring the transfusion of 4 or more units of red cells within the first 72 hours after surgery, cardiac arrest requiring cardiopulmonary resuscitation, coma of 24 hours' duration or more, deep-vein thrombosis, myocardial infarction, unplanned intubation, ventilator use for 48 hours or more, pneumonia, pulmonary embolism, stroke, major disruption of wound, infection of surgical site, sepsis, septic shock, the systemic inflammatory response syndrome, unplanned return to the operating room, vascular graft failure, and death. Urinary tract infection was not considered a major complication. A group of physician reviewers determined, by consensus, whether postoperative events reported as "other complications" qualified as major complications, using the Clavien classification for guidance. ${ }^{18}$

We assessed adherence to a subgroup of six safety measures as an indicator of process adherence. The six measures were the objective evaluation and documentation of the status of the patient's airway before administration of the anesthetic; the use of pulse oximetry at the time of initiation of anesthesia; the presence of at least two peripheral intravenous catheters or a central venous catheter before incision in cases involving an estimated blood loss of $500 \mathrm{ml}$ or more; the administration of prophylactic antibiotics within 60 minutes before incision except in the case of preexisting infection, a procedure not involving incision, or a contaminated operative field; oral confirmation, immediately before incision, of the

\begin{tabular}{|ccccccc|}
\hline \multicolumn{2}{l}{ Table 3. Surgical Safety Policies in Place at Participating Hospitals before the Study. } \\
$\begin{array}{c}\text { Routine } \\
\text { Intraoperative } \\
\text { Monitoring with } \\
\text { Pulse Oximetry }\end{array}$ & $\begin{array}{c}\text { Oral Confirmation } \\
\text { of Patient's Identity } \\
\text { and Surgical Site } \\
\text { in Operating Room }\end{array}$ & $\begin{array}{c}\text { Routine Administration } \\
\text { of Prophylactic Antibiotics } \\
\text { in Operating Room }\end{array}$ & $\begin{array}{c}\text { Standard Plan for } \\
\text { Intravenous Access } \\
\text { for Cases of High } \\
\text { Blood Loss }\end{array}$ & Formal Team Briefing \\
1 & Yes & Yes & Yes & No & Preoperative Postoperative \\
2 & Yes & No & Yes & No & No & No \\
3 & Yes & No & Yes & No & No & No \\
4 & Yes & Yes & Yes & No & No & No \\
5 & No & No & No & No & No & No \\
6 & No & No & Yes & No & No & No \\
7 & Yes & No & No & No & No & No \\
8 & Yes & No & No & No & No & No
\end{tabular}

* Sites 1 through 4 are located in high-income countries; sites 5 through 8 are located in low- or middle-income countries. ${ }^{16}$ 
identity of the patient, the operative site, and the procedure to be performed; and completion of a sponge count at the end of the procedure, if an incision was made. We recorded whether all six of these safety measures were taken for each patient.

\section{STATISTICAL ANALYSIS}

Statistical analyses were performed with the use of the SAS statistical software package, version 9.1 (SAS Institute). To minimize the effect of differences in the numbers of patients at each site, we standardized the rates of various end points to reflect the proportion of patients from each site. These standardized rates were used to compute the frequencies of performance of specified safety measures, major complications, and death at each site before and after implementation of the checklist. ${ }^{19}$ We used logistic-regression analysis to calculate two-sided $\mathrm{P}$ values for each comparison, with site as a fixed effect. We used generalized-estimating-equation methods to test for any effect of clustering according to site.

We performed additional analyses to test the robustness of our findings, including logisticregression analyses in which the presence or absence of a data collector in the operating room and the case mix were added as variables. We classified cases as orthopedic, thoracic, nonobstetric abdominopelvic, obstetric, vascular, endoscop- ic, or other. To determine whether the effect of the checklist at any one site dominated the results, we performed cross-validation by sequentially removing each site from the analysis. Finally, we disaggregated the sites on the basis of whether they were located in high-income or lowor middle-income countries and repeated our analysis of primary end points. All reported $P$ values are two-sided, and no adjustments were made for multiple comparisons.

\section{RESULTS}

We enrolled 3733 patients during the baseline period and 3955 patients after implementation of the checklist. Table 4 lists characteristics of the patients and their distribution among the sites; there were no significant differences between the patients in the two phases of the study.

The rate of any complication at all sites dropped from $11.0 \%$ at baseline to $7.0 \%$ after introduction of the checklist $(\mathrm{P}<0.001)$; the total in-hospital rate of death dropped from 1.5\% to $0.8 \%(\mathrm{P}=0.003)$ (Table 5). The overall rates of surgical-site infection and unplanned reoperation also declined significantly $(\mathrm{P}<0.001$ and $\mathrm{P}=0.047$, respectively). Operative data were collected by the local data collector through direct observation for $37.5 \%$ of patients and by unobserved clinical teams for the remainder. Neither the presence nor

\begin{tabular}{|c|c|c|c|c|c|c|c|c|c|c|c|c|}
\hline \multirow[t]{3}{*}{ Site No. } & \multicolumn{2}{|c|}{$\begin{array}{c}\text { No. of } \\
\text { Patients Enrolled }\end{array}$} & \multicolumn{2}{|c|}{ Age } & \multicolumn{2}{|c|}{ Female Sex } & \multicolumn{2}{|c|}{ Urgent Case } & \multicolumn{2}{|c|}{$\begin{array}{l}\text { Outpatient } \\
\text { Procedure }\end{array}$} & \multicolumn{2}{|c|}{$\begin{array}{c}\text { General } \\
\text { Anesthetic }\end{array}$} \\
\hline & Before & After & Before & After & Before & After & Before & After & Before & After & Before & After \\
\hline & & & \multicolumn{2}{|c|}{ years } & \multicolumn{8}{|c|}{ percent } \\
\hline 1 & 524 & 598 & $51.9 \pm 15.3$ & $51.4 \pm 14.7$ & 58.2 & 62.7 & 7.4 & 8.0 & 31.7 & 31.8 & 95.0 & 95.2 \\
\hline 2 & 357 & 351 & $53.5 \pm 18.4$ & $54.0 \pm 18.3$ & 54.1 & 56.7 & 18.8 & 14.5 & 23.5 & 20.5 & 92.7 & 93.5 \\
\hline 3 & 497 & 486 & $51.9 \pm 21.5$ & $53.0 \pm 20.3$ & 44.3 & 49.8 & 17.9 & 22.4 & 6.4 & 9.3 & 91.2 & 94.0 \\
\hline 4 & 520 & 545 & $57.0 \pm 14.9$ & $56.1 \pm 15.0$ & 48.1 & 49.6 & 6.9 & 1.8 & 14.4 & 11.0 & 96.9 & 97.8 \\
\hline 5 & 370 & 330 & $34.3 \pm 15.0$ & $31.5 \pm 14.2$ & 78.3 & 78.4 & 46.1 & 65.4 & 0.0 & 0.0 & 17.0 & 10.0 \\
\hline 6 & 496 & 476 & $44.6 \pm 15.9$ & $46.0 \pm 15.5$ & 45.0 & 46.6 & 28.4 & 22.5 & 1.4 & 1.1 & 61.7 & 59.9 \\
\hline 7 & 525 & 585 & $37.4 \pm 14.0$ & $39.6 \pm 14.9$ & 69.1 & 68.6 & 45.7 & 41.0 & 0.0 & 0.0 & 49.1 & 55.9 \\
\hline 8 & 444 & 584 & $41.9 \pm 15.8$ & $39.7 \pm 16.2$ & 57.0 & 52.7 & 13.5 & 21.9 & 0.9 & 0.2 & 97.5 & 94.7 \\
\hline Total & 3733 & 3955 & $46.8 \pm 18.1$ & $46.7 \pm 17.9$ & 56.2 & 57.6 & 22.3 & 23.3 & 9.9 & 9.4 & 77.0 & 77.3 \\
\hline \multicolumn{3}{|l|}{$P$ value } & \multicolumn{2}{|c|}{0.63} & \multicolumn{2}{|c|}{0.21} & \multicolumn{2}{|c|}{0.26} & \multicolumn{2}{|c|}{0.40} & \multicolumn{2}{|c|}{0.68} \\
\hline
\end{tabular}

* Plus-minus values are means \pm SD. Urgent cases were those in which surgery within 24 hours was deemed necessary by the clinical team. Outpatient procedures were those for which discharge from the hospital occurred on the same day as the operation. P values are shown for the comparison of the total value after checklist implementation with the total value before implementation. 


\begin{tabular}{|c|c|c|c|c|c|c|c|c|c|c|c|c|}
\hline \multirow[t]{2}{*}{ Site No. } & \multicolumn{2}{|c|}{$\begin{array}{l}\text { No. of Patients } \\
\text { Enrolled }\end{array}$} & \multicolumn{2}{|c|}{$\begin{array}{l}\text { Surgical-Site } \\
\text { Infection }\end{array}$} & \multicolumn{2}{|c|}{$\begin{array}{l}\text { Unplanned Return to } \\
\text { the Operating Room }\end{array}$} & \multicolumn{2}{|c|}{ Pneumonia } & \multicolumn{2}{|c|}{ Death } & \multicolumn{2}{|c|}{ Any Complication } \\
\hline & Before & After & Before & After & Before & After & Before & After & Before & After & Before & After \\
\hline & & & \multicolumn{10}{|c|}{ percent } \\
\hline 1 & 524 & 598 & 4.0 & 2.0 & 4.6 & 1.8 & 0.8 & 1.2 & 1.0 & 0.0 & 11.6 & 7.0 \\
\hline 2 & 357 & 351 & 2.0 & 1.7 & 0.6 & 1.1 & 3.6 & 3.7 & 1.1 & 0.3 & 7.8 & 6.3 \\
\hline 3 & 497 & 486 & 5.8 & 4.3 & 4.6 & 2.7 & 1.6 & 1.7 & 0.8 & 1.4 & 13.5 & 9.7 \\
\hline 4 & 520 & 545 & 3.1 & 2.6 & 2.5 & 2.2 & 0.6 & 0.9 & 1.0 & 0.6 & 7.5 & 5.5 \\
\hline 5 & 370 & 330 & 20.5 & 3.6 & 1.4 & 1.8 & 0.3 & 0.0 & 1.4 & 0.0 & 21.4 & 5.5 \\
\hline 6 & 496 & 476 & 4.0 & 4.0 & 3.0 & 3.2 & 2.0 & 1.9 & 3.6 & 1.7 & 10.1 & 9.7 \\
\hline 7 & 525 & 585 & 9.5 & 5.8 & 1.3 & 0.2 & 1.0 & 1.7 & 2.1 & 1.7 & 12.4 & 8.0 \\
\hline 8 & 444 & 584 & 4.1 & 2.4 & 0.5 & 1.2 & 0.0 & 0.0 & 1.4 & 0.3 & 6.1 & 3.6 \\
\hline Total & 3733 & 3955 & 6.2 & 3.4 & 2.4 & 1.8 & 1.1 & 1.3 & 1.5 & 0.8 & 11.0 & 7.0 \\
\hline \multicolumn{3}{|l|}{$P$ value } & \multicolumn{2}{|c|}{$<0.001$} & \multicolumn{2}{|c|}{0.047} & \multicolumn{2}{|c|}{0.46} & \multicolumn{2}{|c|}{0.003} & \multicolumn{2}{|c|}{$<0.001$} \\
\hline
\end{tabular}

* The most common complications occurring during the first 30 days of hospitalization after the operation are listed. Bold type indicates values that were significantly different (at $\mathrm{P}<0.05)$ before and after checklist implementation, on the basis of $\mathrm{P}$ values calculated by means of the chisquare test or Fisher's exact test. P values are shown for the comparison of the total value after checklist implementation as compared with the total value before implementation.

absence of a direct observer nor changes in case mix affected the significance of the changes in the rate of complications $(\mathrm{P}<0.001$ for both alternative models) or the rate of death $(\mathrm{P}=0.003$ with the presence or absence of direct observation included and $\mathrm{P}=0.002$ with case-mix variables included). Rates of complication fell from 10.3\% before the introduction of the checklist to $7.1 \%$ after its introduction among high-income sites $(\mathrm{P}<0.001)$ and from $11.7 \%$ to $6.8 \%$ among lowerincome sites $(\mathrm{P}<0.001)$. The rate of death was reduced from $0.9 \%$ before checklist introduction to $0.6 \%$ afterward at high-income sites $(\mathrm{P}=0.18)$ and from $2.1 \%$ to $1.0 \%$ at lower-income sites $(\mathrm{P}=0.006)$, although only the latter difference was significant. In the cross-validation analysis, the effect of the checklist intervention on the rate of death or complications remained significant after the removal of any site from the model $(\mathrm{P}<0.05)$. We also found no change in the significance of the effect on the basis of clustering $(\mathrm{P}=0.003$ for the rate of death and $\mathrm{P}=0.001$ for the rate of complications).

Table 6 shows the changes in six measured processes at each site after introduction of the checklist. During the baseline period, all six measured safety indicators were performed for $34.2 \%$ of the patients, with an increase to $56.7 \%$ of patients after implementation of the checklist
$(\mathrm{P}<0.001)$. At each site, implementation of the checklist also required routine performance of team introductions, briefings, and debriefings, but adherence rates could not be measured.

\section{DISCUSSION}

Introduction of the WHO Surgical Safety Checklist into operating rooms in eight diverse hospitals was associated with marked improvements in surgical outcomes. Postoperative complication rates fell by $36 \%$ on average, and death rates fell by a similar amount. All sites had a reduction in the rate of major postoperative complications, with a significant reduction at three sites, one in a high-income location and two in lower-income locations. The reduction in complications was maintained when the analysis was adjusted for case-mix variables. In addition, although the effect of the intervention was stronger at some sites than at others, no single site was responsible for the overall effect, nor was the effect confined to high-income or low-income sites exclusively. The reduction in the rates of death and complications suggests that the checklist program can improve the safety of surgical patients in diverse clinical and economic environments.

Whereas the evidence of improvement in surgical outcomes is substantial and robust, the ex- 
act mechanism of improvement is less clear and most likely multifactorial. Use of the checklist involved both changes in systems and changes in the behavior of individual surgical teams. To implement the checklist, all sites had to introduce a formal pause in care during surgery for preoperative team introductions and briefings and postoperative debriefings, team practices that have previously been shown to be associated with improved safety processes and attitudes ${ }^{14,20,21}$ and with a rate of complications and death reduced by as much as $80 \% .^{13}$ The philosophy of ensuring the correct identity of the patient and site through preoperative site marking, oral confirmation in the operating room, and other measures proved to be new to most of the study hospitals.

In addition, institution of the checklist required changes in systems at three institutions, in order to change the location of administration of antibiotics. Checklist implementation encouraged the administration of antibiotics in the operating room rather than in the preoperative wards, where delays are frequent. The checklist provided additional oral confirmation of appropriate antibiotic use, increasing the adherence rate from 56 to $83 \%$; this intervention alone has been shown to reduce the rate of surgical-site infection by 33 to $88 \% .^{22-28}$ Other potentially lifesaving measures were also more likely to be instituted, including an objective airway evaluation and use of pulse oximetry, though the change in these measures was less dramatic. ${ }^{15}$ Although the omission of individual steps was still frequent, overall adherence to the subgroup of six safety indicators increased by two thirds. The sum of these individual systemic and behavioral changes could account for the improvements observed.

Another mechanism, however, could be the Hawthorne effect, an improvement in performance due to subjects' knowledge of being observed. ${ }^{29}$ The contribution of the Hawthorne effect is difficult to disentangle in this study. The checklist is orally performed by peers and is intentionally designed to create a collective awareness among surgical teams about whether safety processes are being completed. However, our analysis does show that the presence of study personnel in the operating room was not responsible for the change in the rate of complications.

This study has several limitations. The design, involving a comparison of preintervention data

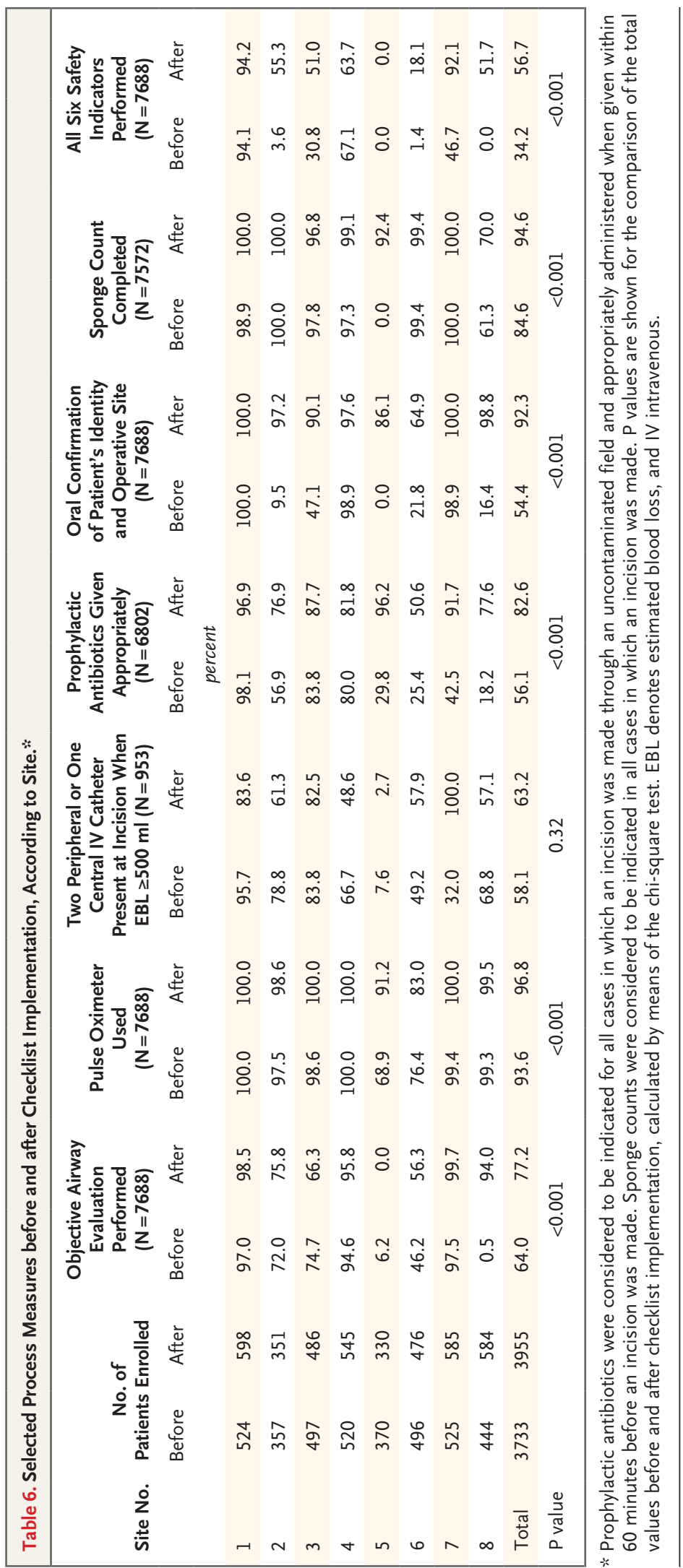


with postintervention data and the consecutive recruitment of the two groups of patients from the same operating rooms at the same hospitals, was chosen because it was not possible to randomly assign the use of the checklist to specific operating rooms without significant cross-contamination. One danger of this design is confounding by secular trends. We therefore confined the duration of the study to less than 1 year, since a change in outcomes of the observed magnitude is unlikely to occur in such a short period as a result of secular trends alone. In addition, an evaluation of the American College of Surgeons' National Surgical Quality Improvement Program cohort in the United States during 2007 did not reveal a substantial change in the rate of death and complications (Ashley S. personal communication, http://acsnsqip.org). We also found no change in our study groups with regard to the rates of urgent cases, outpatient surgery, or use of general anesthetic, and we found that changes in the case mix had no effect on the significance of the outcomes. Other temporal effects, such as seasonal variation and the timing of surgical training periods, were mitigated, since the study sites are geographically mixed and have different cycles of surgical training. Therefore, it is unlikely that a temporal trend was responsible for the difference we observed between the two groups in this study.

Another limitation of the study is that data collection was restricted to inpatient complications. The effect of the intervention on outpatient complications is not known. This limitation is particularly relevant to patients undergoing outpatient procedures, for whom the collection of outcome data ceased on their discharge from the hospital on the day of the procedure, resulting in an underestimation of the rates of complica- tions. In addition, data collectors were trained in the identification of complications and collection of complications data at the beginning of the study. There may have been a learning curve in the process of collecting the data. However, if this were the case, it is likely that increasing numbers of complications would be identified as the study progressed, which would bias the results in the direction of an underestimation of the effect.

One additional concern is how feasible the checklist intervention might be for other hospitals. Implementation proved neither costly nor lengthy. All sites were able to introduce the checklist over a period of 1 week to 1 month. Only two of the safety measures in the checklist entail the commitment of significant resources: use of pulse oximetry and use of prophylactic antibiotics. Both were available at all the sites, including the low-income sites, before the intervention, although their use was inconsistent.

Surgical complications are a considerable cause of death and disability around the world. ${ }^{3}$ They are devastating to patients, costly to health care systems, and often preventable, though their prevention typically requires a change in systems and individual behavior. In this study, a checklistbased program was associated with a significant decline in the rate of complications and death from surgery in a diverse group of institutions around the world. Applied on a global basis, this checklist program has the potential to prevent large numbers of deaths and disabling complications, although further study is needed to determine the precise mechanism and durability of the effect in specific settings.

\footnotetext{
Supported by grants from the World Health Organization.

No potential conflict of interest relevant to this article was
} reported.

\section{APPENDIX}

The members of the Safe Surgery Saves Lives Study Group were as follows: Amman, Jordan: A.S. Breizat, A.F. Awamleh, O.G. Sadieh; Auckland, New Zealand: A.F. Merry, S.J. Mitchell, V. Cochrane, A.-M. Wilkinson, J. Windsor, N. Robertson, N. Smith, W. Guthrie, V. Beavis; Ifakara, Tanzania: P. Kibatala, B. Jullu, R. Mayoka, M. Kasuga, W. Sawaki, N. Pak; London, England: A. Darzi, K. Moorthy, A. Vats, R. Davies, K. Nagpal, M. Sacks; Manila, Philippines: T. Herbosa, M.C.M. Lapitan, G. Herbosa, C. Meghrajani; New Delhi, India: S. Joseph, A. Kumar, H. Singh Chauhan; Seattle, Washington: E.P. Dellinger, K. Gerber; Toronto, Canada: R.K. Reznick, B. Taylor, A. Slater; Boston, Massachusetts: W.R. Berry, A.A. Gawande, A.B. Haynes, S.R. Lipsitz, T.G. Weiser; Geneva, Switzerland: L. Donaldson, G. Dziekan, P. Philip; Baltimore, Maryland: M. Makary; Ankara, Turkey: I. Sayek; Sydney, Australia: B. Barraclough.

REFERENCES

1. Weiser TG, Regenbogen SE, Thompson $\mathrm{KD}$, et al. An estimation of the global volume of surgery: a modelling strategy based on available data. Lancet 2008;372: 139-44.

2. Ronsmans C, Graham WJ. Maternal mortality: who, when, where, and why. Lancet 2006;368:1189-200.

3. Debas HT, Gosselin R, McCord C, 
Thind A. Surgery. In: Jamison DT, Breman JG, Measham AR, et al., eds. Disease control priorities in developing countries. 2nd ed. Disease Control Priorities Project. Washington, DC: International Bank for Reconstruction and Development/World Bank, 2006:1245-60.

4. Gawande AA, Thomas EJ, Zinner MJ, Brennan TA. The incidence and nature of surgical adverse events in Colorado and Utah in 1992. Surgery 1999;126:66-75.

5. Kable AK, Gibberd RW, Spigelman AD. Adverse events in surgical patients in Australia. Int J Qual Health Care 2002;14 269-76.

6. Bickler SW, Sanno-Duanda B. Epidemiology of paediatric surgical admissions to a government referral hospital in the Gambia. Bull World Health Organ 2000;78: 1330-6.

7. Yii MK, Ng KJ. Risk-adjusted surgical audit with the POSSUM scoring system in a developing country. Br J Surg 2002;89: 110-3.

8. McConkey SJ. Case series of acute abdominal surgery in rural Sierra Leone. World J Surg 2002;26:509-13.

9. Ouro-Bang'na Maman AF, Tomta K, Ahouangbévi S, Chobli M. Deaths associated with anaesthesia in Togo, West Africa. Trop Doct 2005;35:220-2.

10. Dellinger EP, Hausmann SM, Bratzler DW, et al. Hospitals collaborate to decrease surgical site infections. Am J Surg 2005;190:9-15.

11. Classen DC, Evans RS, Pestotnik SL, Horn SD, Menlove RL, Burke JP. The timing of prophylactic administration of antibiotics and the risk of surgical-wound infection. N Engl J Med 1992;326:281-6.
12. Runciman WB. Iatrogenic harm and anaesthesia in Australia. Anaesth Intensive Care 2005;33:297-300.

13. Mazzocco K, Petitti DB, Fong KT, et al. Surgical team behaviors and patient outcomes. Am J Surg 2008 September 11 (Epub ahead of print).

14. Lingard L, Regehr G, Orser B, et al. Evaluation of a preoperative checklist and team briefing among surgeons, nurses, and anesthesiologists to reduce failures in communication. Arch Surg 2008;143: 12-8.

15. World Alliance for Patient Safety. WHO guidelines for safe surgery. Geneva: World Health Organization, 2008.

16. World Bank. Data \& statistics: country classification. (Accessed January 5, 2009, at http://go.worldbank.org/K2CKM78CC0.) 17. Khuri SF, Daley J, Henderson W, et al. The National Veterans Administration Surgical Risk Study: risk adjustment for the comparative assessment of the quality of surgical care. J Am Coll Surg 1995;180: 519-31.

18. Dindo D, Demartines N, Clavien PA. Classification of surgical complications: a new proposal with evaluation in a cohort of 6336 patients and results of a survey. Ann Surg 2004;240:205-13.

19. Fleiss JL, Levin B, Paik MC. Statistical methods for rates and proportions. 3rd ed. Hoboken, NJ: John Wiley, 2003.

20. Sexton JB, Makary MA, Tersigni AR, et al. Teamwork in the operating room: frontline perspectives among hospitals and operating room personnel. Anesthesiology 2006;105:877-84.

21. Makary MA, Sexton JB, Freischlag JA, et al. Operating room teamwork among physicians and nurses: teamwork in the eye of the beholder. J Am Coll Surg 2006;202:746-52.

22. Platt R, Zaleznik DF, Hopkins CC, et al. Perioperative antibiotic prophylaxis for herniorrhaphy and breast surgery. N Engl J Med 1990;322:153-60.

23. Austin TW, Coles JC, Burnett R, Goldbach $M$. Aortocoronary bypass procedures and sternotomy infections: a study of antistaphylococcal prophylaxis. Can J Surg 1980;23:483-5.

24. Baum ML, Anish DS, Chalmers TC Sacks HS, Smith H Jr, Fagerstrom RM. A survey of clinical trials of antibiotic prophylaxis in colon surgery: evidence against further use of no-treatment controls. N Engl J Med 1981;305:795-9.

25. Bernard HR, Cole WR. The prophylaxis of surgical infection: the effect of prophylactic antimicrobial drugs on the incidence of infection following potentially contaminated operations. Surgery 1964 . 56:151-7.

26. Hasselgren PO, Ivarsson L, Risberg B, Seeman T. Effects of prophylactic antibiotics in vascular surgery: a prospective, randomized, double-blind study. Ann Surg 1984;200:86-92.

27. Barker FG II. Efficacy of prophylactic antibiotics for craniotomy: a meta-analysis. Neurosurgery 1994;35:484-92.

28. Norden CW. Antibiotic prophylaxis in orthopedic surgery. Rev Infect Dis 1991;13: Suppl 10:S842-S846.

29. Mayo E. The human problems of an industrial civilization. New York: Macmillan, 1933

Copyright $\odot 2009$ Massachusetts Medical Society. 